\title{
Unstable angina early after aortic valve replacement surgery in a female patient with normal coronary arteries preoperatively - a
} case report Sybille Gruber ${ }^{1}$, Choi-Keung Ng${ }^{2}$, Christian Schwarz ${ }^{2}$ and Johann Auer*1,3

\author{
Address: ${ }^{1}$ Department of Cardiology and Intensive Care, General Hospital Braunau, Austria, ${ }^{2}$ Department of Cardiac Surgery, General Hospital \\ Wels, Austria and ${ }^{3}$ Department of Cardiology and Intensive Care, General Hospital Simbach, Germany \\ Email: Sybille Gruber - sybille_gruber@yahoo.com; Choi-Keung Ng - choi.keung.ng@liwest.at; \\ Christian Schwarz - christian.schwarz@klinikum-wegr.at; Johann Auer* - johann.auer@khbr.at \\ * Corresponding author
}

Published: 2 July 2009

Journal of Cardiothoracic Surgery 2009, 4:29 doi:10.1186/1749-8090-4-29

Received: 17 April 2009

Accepted: 2 July 2009

This article is available from: http://www.cardiothoracicsurgery.org/content/4/I/29

(C) 2009 Gruber et al; licensee BioMed Central Ltd.

This is an Open Access article distributed under the terms of the Creative Commons Attribution License (http://creativecommons.org/licenses/by/2.0), which permits unrestricted use, distribution, and reproduction in any medium, provided the original work is properly cited.

\begin{abstract}
Background: Angina pectoris early after aortic valve replacement surgery in patients with previously normal coronary arteries may be life threatening and has to be assessed immediately.

Case report: 12 weeks after aortic valve replacement surgery, a 60-year-old female patient was referred for evaluation of recent onset of severe chest pain on mild exertion and at rest. Coronary angiography showed severe stenosis nvolving the left coronary ostium and the left main stem. The patient was urgently referred for bypass surgery and had an uneventful postoperative recovery.
\end{abstract}

Conclusion: A high degree of suspicion is needed for early recognition and aggressive management of this rare but serious complication.

\section{Background}

Unstable angina is rare, but may be life-threatening in patients in the early postoperative period following aortic valve replacement with normal preoperative coronary arteries.

\section{Methods and results}

We report the case of a 60-year-old female patient undergoing valve replacement surgery for symptomatic aortic valve stenosis. Preoperative echocardiographic assessment revealed a severely calcified aortic valve with a calculated aortic valve area of $0.8 \mathrm{ccm}$. Mean pressure gradient was $55 \mathrm{mmHg}$ and left ventricular ejection fraction was well preserved.

The patient was free of angina and reported dyspnoea on exertion.
Preoperative coronary angiography revealed normal coronary arteries.

Valve replacement surgery was performed using a Sorin 23 $\mathrm{mm}$ mechanical valve prosthesis. Early postoperative recovery was unremarkable.

12 weeks after surgery the patient was referred for evaluation of recent onset of severe chest pain on mild exertion and at rest.

ECG revealed severe ST-segment depression in leads V2-5 during episodes of chest pain.

Coronary angiography showed a 90\% diameter reduction involving the left coronary ostium and the left main stem. 
The patient was urgently referred for bypass surgery and had an uneventful postoperative recovery.

\section{Conclusion}

Angina pectoris early after aortic valve replacement surgery in patients with previously normal coronary arteries may be life threatening and has to be assessed immediately. A high degree of suspicion is needed for early recognition and aggressive management of this rare but serious complication.

\section{Introduction}

Unstable angina early after aortic valve replacement in patients with normal coronary arteries in the preoperative angiography is rare.

Generally, possible differential diagnoses of postoperative angina pectoris in patients undergoing mechanical aortic valve replacement are coronary embolism, progression of coronary heart disease in patients with coronary atherosclerosis, graft occlusion in patients with concomitant aortocoronary bypass (ACBP) and iatrogenic coronary ostial/ main stem stenosis.

Many cases of iatrogenic coronary ostial/main stem stenoses have been reported since the late 1960ies, all cases showing similar patterns - sudden onset of angina pectoris 3-6 months postoperatively in patients without or with only mild coronary artery disease - and similar histologic findings - intimal fibrous proliferation of one or both coronary ostia [1-9].

\section{Patient and methods}

We report the case of a 60-year-old moderately obese female patient, who was referred for evaluation of recent onset dyspnea on exertion. Physical examination revealed a $3 / 6$ crescendeo-decrescendo systolic murmur at the aortic valve.

Electrocardiography showed regular sinus rhythm without additional findings (Fig. 1)

Echocardiographic assessment revealed a severely calcified aortic valve with a calculated valve area of $0,80 \mathrm{~cm}^{2}$ and a mean pressure gradient of $55 \mathrm{mmHg}$.

Left ventricular ejection fraction was well preserved with left ventricular wall thickness of $14 \mathrm{~mm}$ (septal and posterolateral).

Preoperative coronary angiography revealed completely normal coronary arteries (Fig 2).

The patient underwent aortic valve replacement surgery. The procedure was performed using mini-sternotomy with a single 2 -stage venous cannula and normothermic

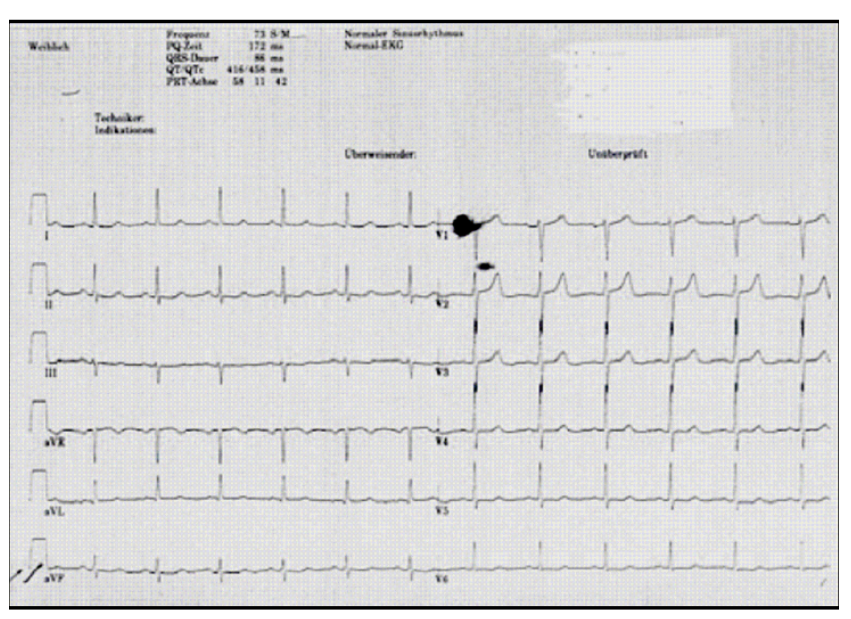

Figure I

Preopoerative ECG: Regular sinus rhythm.

cardiopulmonary bypass. The use of normothermic techniques has been reported to confer several advantages over conventional hypothermia, such as reduced bleeding and requirements for electrical defibrillation, shorter intubation times, and improved hemodynamic parameters postoperatively. Myocardial protection with cold antegrade and retrograde St. Thomas' cardioplegic (II) solution was obtained immediately after aortic cross

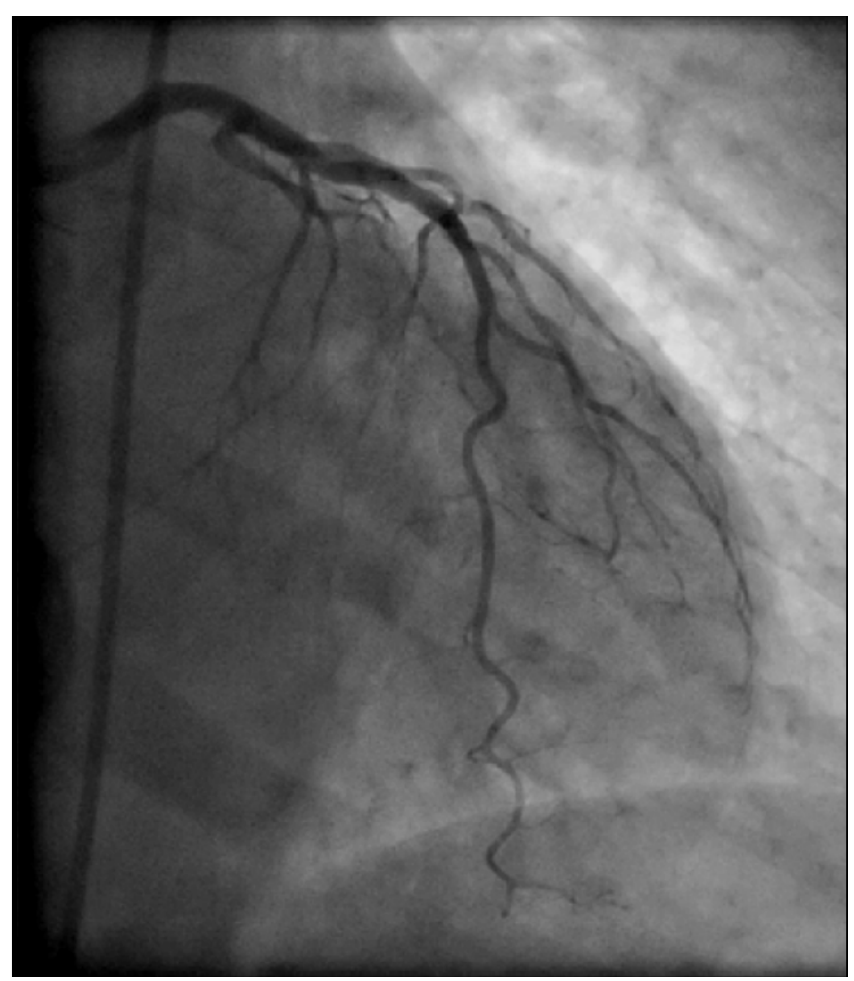

Figure 2

Preoperative coronary angiography (RAO view) showing the left coronary artery. 
clamping. The aortic valve is exposed through an oblique aortotomy incision made well above the orifice of the right coronary artery. The severely calcified stenotic aortic valve was excised, replaced with a Sorin $23 \mathrm{~mm}$ mechanical valve prosthesis, attached with subannular mattress sutures of 2-0 Ethibond (Ethicon, Sommerville, New Jersey, USA).

Early postoperative recovery was unremarkable.

12 weeks after surgery the patient was referred for evaluation of recent onset of severe chest pain on mild exertion and at rest. ECG at admission showed inverted T-waves in leads V2 to V5 and in lead aVL (Fig. 3).

During episodes of chest pain ECG revealed severe ST-segment depression in leads V2 to V5 (Fig 4).

Coronary angiography showed a 90\% diameter reduction involving the left coronary ostium and the left main stem (Fig 5).

The patient was urgently referred for bypass surgery with a left internal mammary artery graft to the LAD and a left radial artery graft to the circumflex artery.

Postoperative recovery was unremarkable. Four months later she is doing well without chest pain or signs of myocardial ischemia.

\section{Discussion}

The present case underlines the importance of early diagnosis and treatment if angina pectoris occurs after aortic valve replacement.

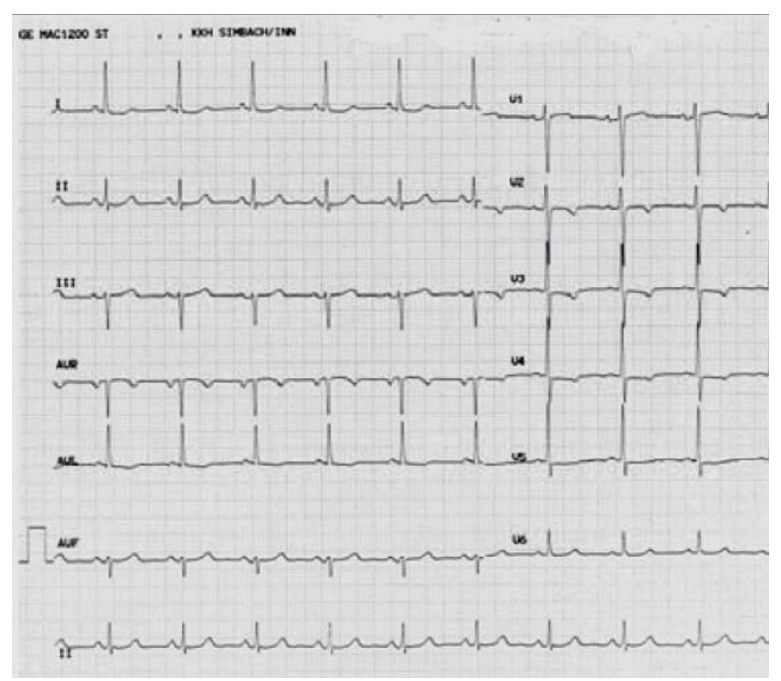

Figure 3

ECG at admission three months after valve replacement with ST-T-abnormalities in the anterior leads.

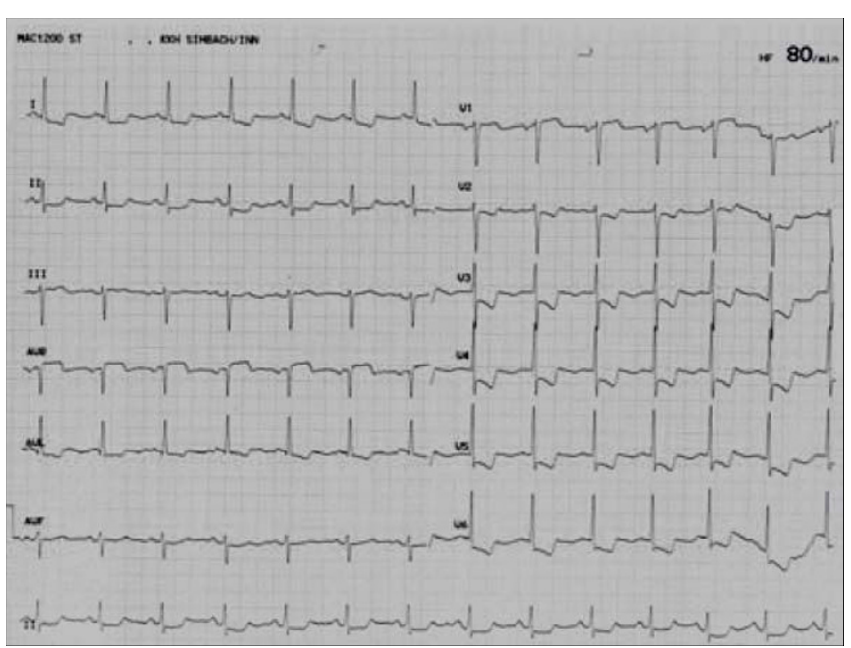

Figure 4

ST segment depressions during severe angina at rest.

Coronary ostial stenoses can be detected in $0,1 \%$ of coronary angiographies in unselected patients $[10,11]$. Apart from atherosclerosis as the prime genesis, thromboses as well as infections (lues) can provoke ostial stenoses. There has also been a report about solitary ostial stenosis in a patient with Takayasu's arteritis [12].

Iatrogenic coronary ostial stenosis is a well recognized, but uncommon and potentially life threatening complication of aortic valve replacement. Symptoms include chest pain during exercise or at rest, sudden onset of acute heart failure and acute pulmonary edema. Usually, symptoms

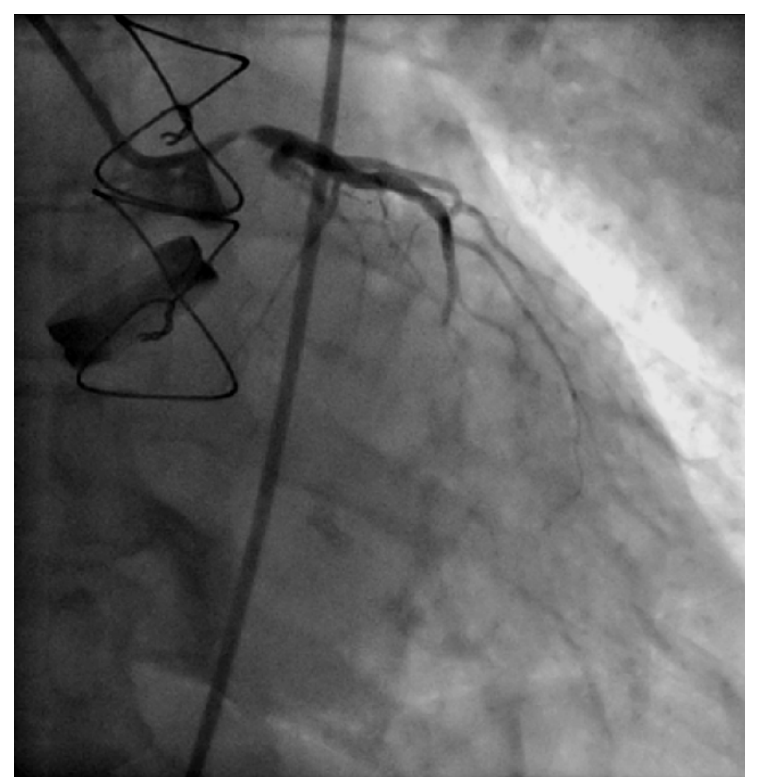

Figure 5

Postoperative coronary angiography (RAO view) showing the left coronary artery. 
occur within the first 6 months, though they may occur up to 30 months after the operation [1].

Main stem stenosis after aortic valve replacement was first recognised in 1969 by Trimble et al [2]. who described the cases of three patients who underwent surgery for aortic valve stenosis and/or insufficiency in 1965. Three to four months after the operation they developed angina pectoris, in each case coronary angiography showed severe stenosis of either one or both coronary ostia. According to Lesage et al. the incidence of this severe complication may be as high as $0.9 \%$ [3] - however, incidence is decreasing, because of improved operative techniques [4].

Several pathogenic mechanisms have been suggested: aortic root fibrosis secondary to turbulent flow around the prosthesis [13]; the presence of perfusion catheters during valve surgery that produce local pressure necrosis and subsequent intimal proliferation leading to obstruction of the coronary ostia [2]; balloon inflation in the proximal parts of the vessels; turbulence that causes coronary artery intimal injury that might explain the lesions often found distant to the adherence of the cannulation devices; immunologic reaction after valve replacement with heterograft [5].

There may also be a genetic predisposition for developing this complication since $70 \%$ of the affected individuals as compared to $10-15 \%$ in a control group had an epsilon 4 allele apolipoprotein E genotype [6].

Instrumentation with minimal trauma of the left main stem is most likely the cause of early postoperative stenosis after aortic valve replacement surgery $[7,8,14]$.

Avoiding cannulation of the coronary ostia for antegrade cardioplegia, but instead using retrograde delivery as an alternative method for myocardial perfusion during open heart surgery may reduce the risk of postoperative coronary ostial or left main stem stenosis $[9,15]$.

\section{Conclusion}

If recurrent or newly onset angina pectoris occurs early after aortic valve

Replacement, a high degree of suspicion os warranted to recognize this rare but life threatening complication of coronary ostial stenosis, even if preoperative coronary angiography did not show coronary heart disease.

New operative techniques that reduce manipulation and consequently avoid trauma of the coronary vessels may prevent postoperative coronary ostial stenosis. Future studies in patients undergoing this procedure using retrograde cardioplegia only will have to prove this hypothesis.

\section{Consent}

Written informed consent was obtained from the patient for publication of this case report and accompanying images. A copy of the written consent is available for review by the Editor-in-Chief of this journal.

\section{Competing interests}

The authors declare that they have no competing interests.

\section{Authors' contributions}

SG was the main author and wrote the article. CKN was the surgical consultant, was involved in data collection and revised the manuscript. CS was the surgical consultant was involved in data collection and interpretation. JA was the cardiology consultant and gave final approval of the manuscript. All authors have read and approved the final manuscript.

\section{References}

I. Hadjimiltiades S, Harokopos N, Papadopoulos C, Gourassas I, Spanos P, Louridas G: Left Main Coronary Artery Stenosis after Aortic Valve Replacement. Hellenic J Cardiol 2005, 46(4):306-309.

2. Trimble AS, Bigelow WG, Wigle ED, Silver MD: Coronary ostial stenosis. A late complication of coronary perfusion in openheart surgery. J Thorac Cardiovasc Surg 1969, 57(6):792-795.

3. Lesage $\mathrm{CH}$, Vogel JH, Blount SG: latrogenic coronary occlusive disease in patients with prosthetic heart valves. Am J Cardiol 1970, 26:123-129.

4. DePace NL, Lenwle GM, Wolf NW, Dowinsky S, Untereker W, Spagna PM: Total Left Main Coronary Artery Occlusion after Aortic Aneurysm Repair and Valve Replacement. Chest I99I, 99:515-517.

5. Tsukiji M, Akasaka T, Wada N, Okahashi N, Kume T, Yoshitani H, Neishi Y, Watanabe N, Yoshida K: Bilateral coronary ostial stenosis after aortic valve replacement with freestyle stentless bioprosthesis: a case report. J Cardiol 2004, 44:207-13.

6. Winkelmann BR, Ihnken K, Beyersdorf F: Left main coronary artery stenosis after aortic valve replacement: genetic predisposition for accelerated arteriosclerosis after injury of the intact human coronary artery? Coron Artery Dis 1993, 4:659-667.

7. Roberts WC, Morrow AG: Late postoperative pathological findings after cardiac valve replacement. Circulation. 1967, 35(4 Suppl ):148-162.

8. Roithinger FX, Berent R, Punzengruber C, Maurer E, Ng CK, Hartl P, Pachinger O: Ostium stenosis of the left coronary artery after aortic valve replacement-2 case reports. Wien Klin Wochenschr 1996, 108:552-4.

9. Menasché P, Subayi JB, Piwnica A: Retrograde coronary sinus cardioplegia for aortic valve operations: a clinical report on $\mathbf{5 0 0}$ patients. Ann Thorac Surg 1990, 49:556-63.

10. Yamanaka O, Hobbs RE: Solitary ostial coronary artery stenosis. Jpn Circ J 1993, 57:404-10.

II. Sasaguri S, Honda $Y$, Kanou T: Isolated coronary ostial stenosis compared with left main trunk disease. Jpn Circ J 1991, 55:| $|87-9|$.

12. Noma M, Sugihara M, Kikuchi Y: Isolated Coronary Ostial Stenosis in Takayasu's Arteritis: Case Report and Review of the Literature. Angiology 1993, 44:839-844.

13. Reed GE, Spencer FC, Boyd AD, Engelman RM, Glassman E: Late complications of intraoperative coronary artery perfusion. Circulation 1973, 48( I Suppl):III80-III84.

14. Pillai JB, Pillay TM, Ahmad J: Coronary Ostial Stenosis After Aortic Valve Replacement, Revisited. Ann Thorac Surg 2004, 78:2169-2I7I.

15. Sethi G, Scott $S$, Takaro $T$ : latrogenic coronary artery stenosis following aortic valve replacement. I Thorac Cardiovasc Surg 1979, 77:760-767. 